\title{
Social Network Predicts Exposure to Respiratory Infection in a Wild Chimpanzee Group
}

\author{
Aaron A. Sandel@ ${ }^{1}$ Julie Rushmore, ${ }^{2,3}$ Jacob D. Negrey, ${ }^{4}$ John C. Mitani, ${ }^{5}$ \\ Daniel M. Lyons, ${ }^{6}$ and Damien Caillaud ${ }^{7}$ \\ ${ }^{1}$ Department of Anthropology, University of Texas at Austin, 2201 Speedway Stop C3200, Austin, TX 78712 \\ ${ }^{2}$ One Health Institute, School of Veterinary Medicine, University of California, Davis, CA \\ ${ }^{3}$ Epicenter for Disease Dynamics, School of Veterinary Medicine, University of California, Davis, CA \\ ${ }^{4}$ Department of Pathobiological Sciences, University of Wisconsin, Madison, WI \\ ${ }^{5}$ Department of Anthropology, University of Michigan, Ann Arbor, MI \\ ${ }^{6}$ Department of Ecology and Evolutionary Biology, University of Michigan, Ann Arbor, MI \\ ${ }^{7}$ Department of Anthropology, University of California, Davis, CA
}

\begin{abstract}
Respiratory pathogens are expected to spread through social contacts, but outbreaks often occur quickly and unpredictably, making it challenging to simultaneously record social contact and disease incidence data, especially in wildlife. Thus, the role of social contacts in the spread of infectious disease is often treated as an assumption in disease simulation studies, and few studies have empirically demonstrated how pathogens spread through social networks. In July-August 2015, an outbreak of respiratory disease was observed in a wild chimpanzee community in Kibale National Park, Uganda, during an ongoing behavioral study of male chimpanzees, offering a rare opportunity to evaluate how social behavior affects individual exposure to socially transmissible diseases. From May to August 2015, we identified adult and adolescent male chimpanzees displaying coughs and rhinorrhea and recorded $5-\mathrm{m}$ proximity data on males $(N=40)$. Using the network $\mathrm{k}$ test, we found significant relationships between male network connectivity and the distribution of cases within the network, supporting the importance of short-distance contacts for the spread of the respiratory outbreak. Additionally, chimpanzees central to the network were more likely to display clinical signs than those with fewer connections. Although our analyses were limited to male chimpanzees, these findings underscore the value of social connectivity data in predicting disease outcomes and elucidate a potential evolutionary cost of being social.
\end{abstract}

Keywords: Pathogens, Sociality, Contact network, Primates, Cough, Dominance

Supplementary information: The online version of this article (https://doi.org/10. 1007/s10393-020-01507-7) contains supplementary material, which is available to authorized users.

Julie Rushmore, Jacob D. Negrey, and Damien Caillaud have contributed equally.

Published online: January 6, 2021

Correspondence to: Aaron A. Sandel, e-mail: aaron.sandel@austin.utexas.edu

\section{InTRODUCTION AND PuRPOSE}

Group life is important for many species as it may reduce the risk of predation and improve foraging efficiency, but one major cost of sociality is the increased opportunity for direct pathogen transmission (Alexander 1974; Krause and 
Ruxton 2002; Altizer et al. 2003; Rifkin et al. 2012; Kappeler et al. 2015). Contact networks have emerged as a valuable way to examine how social interactions influence pathogen transmission, especially for species with heterogeneous contact rates (Craft and Caillaud 2011; Rushmore 2014; Craft 2015; Reynolds et al. 2015; Croft et al. 2016; Romano et al. 2016; Webber et al. 2016; Springer et al. 2017). Several recent examples have demonstrated strong correlations between social networks and transmission networks. For example, social networks have been associated with tuberculosis infection in meerkats (Drewe 2010), Salmonella enterica in sleepy lizards (Bull et al. 2012), chronic wasting disease in mule deer (Salazar et al. 2016), skin disease in dolphins (Powell 2019), and Escherichia coli in opossums (Blyton et al. 2014), giraffe (VanderWaal et al. 2014), and captive rhesus macaques (Balasubramaniam et al. 2019). Theoretical models have generalized these empirical findings for wildlife by showing that in heterogeneous contact networks, individuals systematically vary in their likelihood to acquire and transmit pathogens to a large number of susceptible individuals (Rushmore et al. 2017; White et al. 2017).

Infectious diseases have emerged as one of the main threats to endangered wildlife populations (Daszak et al. 2000; Smith et al. 2009), and group-living taxa, such as primates, are particularly susceptible (Wolfe et al. 1998; Wallis and Rick Lee 1999; Chapman et al. 2005; Nunn and Gillespie 2016). Some of the best-documented cases of wildlife disease outbreaks concern great apes (Leendertz et al. 2004, 2006; Kaur et al. 2008; Köndgen et al. 2008; Palacios et al. 2011; Grützmacher et al. 2016; Emery Thompson et al. 2018). For example, Ebola devastated wild gorilla populations in the early 2000s (Bermejo et al. 2006; Caillaud et al. 2006). More recently, multiple respiratory disease outbreaks in wild chimpanzees have been linked to zoonotic viruses (Kaur et al. 2008; Köndgen et al. 2008; Williams et al. 2008; Scully et al. 2018; Negrey et al. 2019). Understanding pathogen spread and factors or interventions that influence individual infection risk has therefore become a conservation priority (Nunn et al. 2008; Carne et al. 2013; Rushmore 2014).

Given the impact that directly transmitted diseases have on primate populations, the relationship between social networks and pathogen spread has recently become a focus of research for wild primates. For example, Kuehl et al. (2008) concluded that social contacts increased pathogen transmission in young western chimpanzees after determining that increased infant play behavior corre- sponded to peaks in infant mortality. Another study tracked individually marked lice (Lemurpediculus verruculosus) in a mouse lemur population and provided direct evidence of between-individual transfers during social contacts (Zohdy et al. 2012). Brown spider monkeys that have more physical contact with conspecifics exhibit a higher gastrointestinal parasite species richness than less connected individuals (Rimbach et al. 2015). Similarly, mangabeys that occupy more central positions in proximity networks are more likely to be reinfected by helminths after chemotherapeutic treatment (Friant et al. 2016). Finally, being members of the same social group is a strong predictor of intestinal bacterial flora composition in sifaka (Springer et al. 2016; Perofsky et al. 2017). In addition to social connectivity, dominance status is associated with gastrointestinal helminthic parasite infection in wild chimpanzees (Muehlenbein and Watts 2010), nematode infection in Japanese macaques (MacIntosh et al. 2012), and influences immune function in macaques (Tung et al. 2012; Snyder-Mackler et al. 2016), although this pattern is inconsistent across species (Habig and Archie 2015). Indeed, the influence of dominance status and social network position on infection may vary depending on the specific disease or parasite in question (MacIntosh et al. 2012).

Social connectivity and social status appear to influence exposure to infection in wild primates, but the role of sociality in shaping respiratory outbreaks-a major conservation threat for great apes-remains poorly documented (Vogel 2003; Leendertz et al. 2006; Rushmore et al. 2013; Rushmore 2014; Romano et al. 2016; Emery Thompson et al. 2018; Scully et al. 2018; Negrey et al. 2019). Chimpanzees are an ideal taxon for exploring links between sociality and infection due to their fission-fusion social dynamics. The members of a chimpanzee community rarely are all together at the same time; instead, individuals form temporary subgroups that last a few hours to a few days (Nishida 1968; Goodall 1986). Within-community variation in sociality creates heterogeneity and potential sub-structuring, increasing the chance of detecting whether pathogen transmission tracks the underlying contact network. In addition, adult male chimpanzees form a linear dominance hierarchy, which allows assessment of the interconnection between dominance rank, social contacts, and infection status (e.g., Rushmore et al. 2013).

In July and August 2015, the Ngogo chimpanzees of Kibale National Park, Uganda, experienced an outbreak of non-lethal respiratory disease, which we report here for the first time. The outbreak occurred during an ongoing study 
of male chimpanzee behavior, providing a rare opportunity to examine the role of social networks in predicting disease outcomes for an acute respiratory pathogen in a wildlife population. Here, we test if social contacts influenced the distribution of clinical signs among male chimpanzees, using data collected on 40 adolescent and adult male chimpanzees from the Ngogo community. We also examined the importance of a male's position in the social network relative to his dominance status and age in predicting the likelihood of exhibiting clinical signs. We tested the hypotheses that (1) contact heterogeneity among dyads affects disease dynamics, and (2) males more central in the network are more likely to exhibit clinical signs, controlling for dominance status and age. We also tested (3) the effect of dominance on centrality and (4) the effect of age on centrality.

\section{Methods}

\section{Study Site and Subjects}

We conducted observations of chimpanzees at Ngogo, Kibale National Park, Uganda ( $\left.00^{\circ} 29^{\prime} 53^{\prime \prime} \mathrm{N}, 30^{\circ} 25^{\prime} 30^{\prime \prime} \mathrm{E}\right)$. Located in the center of the Park, the Ngogo chimpanzee community territory is surrounded on all sides by other chimpanzee communities and the only contact with humans is from researchers and research staff. The habitat consists mostly of mature rainforest interspersed between areas of regenerating forest, grasslands, and swamps (Struhsaker 1997). During the data collection period (May 1 to August 29, 2015), the Ngogo chimpanzee community consisted of 193 individuals, including 53 adult and adolescent males (32 adult males, 21 adolescent males), 78 adult and adolescent females (63 adult females, 15 adolescent females), 15 juveniles (10 males, 5 females), and 46 infants. Ages of chimpanzees are known to the nearest year for subjects under 20 years and estimated based on physical appearance and known genetic relationships for adults over 20 years (Wood et al. 2017).

For the purposes of this study, we focused on 32 adult male chimpanzees (16-53 years) and eight middle-to-late adolescents (12-15 years). Although including all age and sex classes would offer the most complete network for analyzing transmission dynamics (De Nys et al. 2013; Rushmore et al. 2013; Emery Thompson et al. 2018), our focus on males was partly due to methodological constraints: outbreaks are unpredictable, and during the time of the outbreak, we had the greatest precision in social and health data on mature male chimpanzees, as they were the subjects of concurrent studies by two of the authors. Although limiting to a subset of males is not ideal, there was no a priori reason to believe this would skew results. Mature male chimpanzees, especially in East Africa, are more gregarious than adult females (Wrangham and Smuts 1980; Goodall 1986; Gilby and Wrangham 2008; Carne et al. 2013; Langergraber et al. 2013; Machanda et al. 2013) and occupy a larger range within the community territory than adult females (Thompson et al. 2007; Kahlenberg et al. 2008). Thus, the male network is expected to reflect the overall network. This is similar to other studies that have limited networks to the more social sex (MacIntosh et al. 2012; Duboscq et al. 2016; Balasubramaniam et al. 2018). The focus on males is also relevant as male chimpanzees have more clearly defined dominance hierarchies than do females (Wakefield 2008; Foerster et al. 2016), and we aimed to examine the influence of dominance status on clinical signs.

\section{Behavioral Data}

Behavioral and proximity data were collected from May 1 to August 29, 2015 as part of long-term studies on adolescent and adult male chimpanzees. Chimpanzees were observed continuously for 60-min focal-follow episodes, and the identity of chimpanzees within 5 meters of the focal subject was recorded instantaneously at 10-min intervals. To assess dominance status, we used data on pant grunts, a formal signal of submission directed up the hierarchy and given by low-ranking chimpanzees to higher-ranking individuals (Bygott 1979; de Waal 1982). Males were given ordinal ranks (i.e., the alpha male had a rank of 1 , the beta had a rank of 2, etc.), which were then transformed by subtracting the rank from the total number of males in the hierarchy and dividing this by the total number of males minus one. After transformation, the alpha male had a rank of 1 and the lowest-ranking individual had a rank of 0 (Muller et al. 2006).

Because chimpanzees live in fission-fusion societies, not all males were available for observation every day. We balanced the number of focal follows by rotating through subjects on an opportunistic basis, prioritizing males who had been observed less often than others (irrespective of clinical signs). On occasion, chimpanzees were observed twice in a single day, although in such cases focal follows were separated by at least five hours. We conducted a total 
of $659 \mathrm{~h}$ of focal observations representing an average of $16.5 \pm 6.2 \mathrm{~h}$ per study subject.

\section{Health Data}

We conducted health assessments as part of routine observations of all chimpanzees, similar to those used at other chimpanzee sites (Krief et al. 2005; Lonsdorf et al. 2018). Individuals observed to cough or exhibit rhinorrhea (i.e., nasal drainage) more than once on a given day across the study period (regardless of focal status) were considered to have clinical signs of respiratory infection. If observers saw an individual for at least $3 \mathrm{~h}$ on a given day with no clinical signs, they were considered healthy for that day. Agreement among field observers was high (agreement in $13 / 14$ instances when all three observers monitored the same individuals). Males that were never observed to exhibit clinical signs for the duration of the outbreak were considered healthy.

\section{Social Network and Centrality Metrics}

We created an adjacency matrix of pairwise association indices based on proximity data. To calculate an association index for a given pair, we summed the number of scans the pair was observed in proximity, regardless of which individual was the focal subject, and then we divided this by the total number of scans either individual was observed as a focal subject. We built a weighted network, in which nodes represented chimpanzee individuals and edges were weighted according to pairwise association indices.

We used the weighted network to calculate strength centrality, which is the summed edge weight for a given node (Freeman et al. 1991; Newman 2010). We also calculated two other centrality metrics: eigenvector centrality (function of connectedness of a nodes' associates) and flow-betweenness centrality (frequency with which a node is along the shortest path between pairs of nodes). Given that strength was strongly correlated with eigenvector (Spearman's rank correlation, $r_{\mathrm{s}}=0.71$, $P<0.001)$ and flow-betweenness $\left(r_{\mathrm{s}}=0.69, P<0.001\right)$, our statistical analyses focused on strength centrality. We calculated centrality metrics and built social networks in $\mathrm{R}$ ( $\mathrm{R}$ Core Team 2018) using the sna (Butts 2016) and igraph packages (Csardi and Nepusz 2006).

\section{Statistical Analyses}

We assessed the relevance of the social network on clinical signs using two methods. First, we used the path-based ktest to assess whether the topology of chimpanzees with clinical signs in the observed network likely resulted from transmission along network edges (VanderWaal et al. 2016). The path-based k-test assesses if the mean weighted distance between discernibly infected individuals in a weighted network is shorter than expected by chance (VanderWaal et al. 2016). The path-based k-test uses a permutation-based procedure of "node-label swapping" cases of infection are randomly re-assigned within the network-to create a null distribution. We report $\mathrm{p}$ values based on the distribution of the simulated statistics over 1000 randomizations. The k-test is useful for modeling pathogen transmission as it takes into account clustering within the network and is robust to missing nodes and missing cases (VanderWaal et al. 2016). The k-test can be used on social or spatial data, although we limited our analysis to social data and do not assess the relative contribution of shared space use on social structure or pathogen transmission.

We also examined the extent to which the presence of clinical signs was predicted by individual connectivity within the social network, social rank, and age (Rushmore et al. 2013; Habig and Archie 2015). We conducted a logistic regression with a binomial error distribution using the "glm" function in R (R Core Team 2018). The presence/absence of clinical signs was the response variable, and strength centrality, ordinal rank, and age were the predictor variables. To account for the non-independence of data inherent to social network metrics, we assessed variable importance by creating $\mathrm{p}$ values using node-level permutation with 30,000 iterations (Rushmore et al. 2013). Specifically, we calculated the regression using observed data. We then permuted the response variable data and saved estimates after each regression, calculating $\mathrm{p}$ values based on the permuted values. We assessed collinearity of predictor variables using the "vif" function in package car (Fox and Weisberg 2019); all variance inflation factors were less than 2, indicating little-to-no collinearity. In two additional analyses, we conducted node-level permutationbased linear regressions to assess (1) the effect of dominance rank and (2) age on strength centrality.

Individual differences in the number of observations can increase both centrality and the likelihood of detecting sick individuals. We controlled for variation in sampling 
effort by creating dyadic association indices that accounted for time spent observing each chimpanzee in a given dyad. Further, variation in observation hours across individuals did not affect the traits of interest: There was no relationship between number of observations and (a) centrality in the social network $(\beta=-0.001 \pm 0.001, P=0.139)$ or (b) whether a chimpanzee exhibited clinical signs ( $\beta=0.007 \pm 0.009, P=0.425$ ). These analyses suggest to us that we collected sufficient data on each individual such that additional observations did not greatly increase our ability to determine (a) position in the social network and (b) which animals had clinical signs. Nevertheless, there may be patterns in the data that could generate a spurious outcome in a more complex model, which we did not account for here.

\section{Results}

Clinical signs of respiratory infection were observed between July 20 and August 12, 2015 (Fig. 1) with high morbidity and zero mortality. Among adolescent and adult male chimpanzees, 32 out of 53 (60\%) individuals exhibited clinical signs, including cough and/or rhinorrhea, representing 30 of the 40 males $(75 \%)$ for which we had proximity data. We also observed 11 females with clinical signs, which was likely an underestimate, as females were not a focus of the study and were excluded from the analyses. Although it was difficult to estimate a minimum or average duration of clinical signs, a subset of males $(N=20)$ observed with clinical signs over time had a maximum duration of 11 days between onset and recovery.

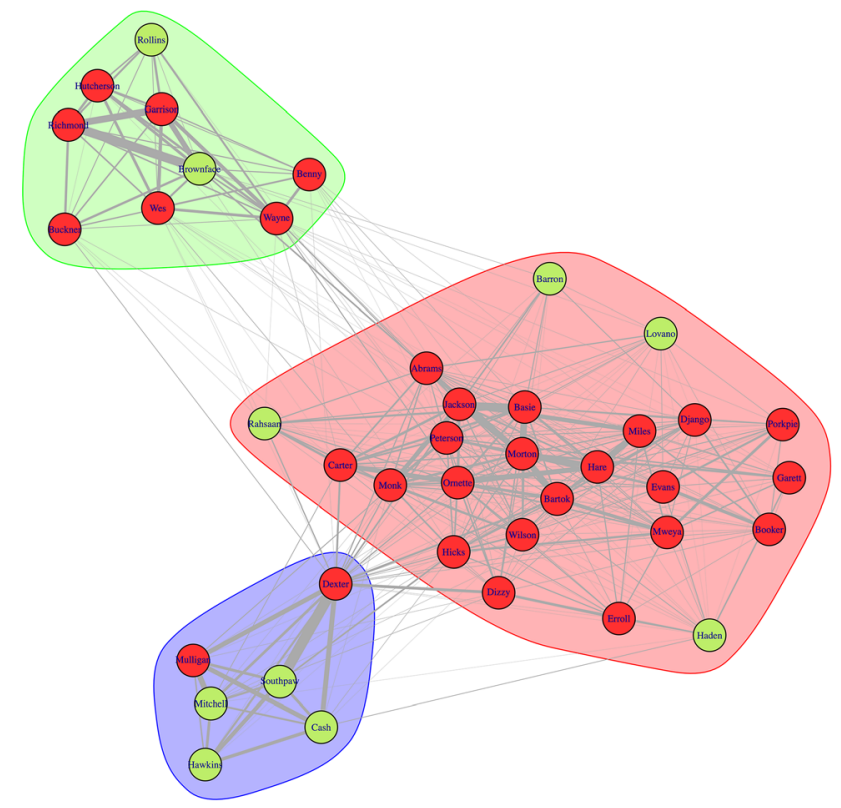

Figure 2. Social network predicts clinical signs of infection. Individual chimpanzees (nodes) are colored according to their presentation (red) or absence (green) of clinical signs. This contact network was created using the Fruchterman-Reingold layout algorithm in R's igraph package. We overlay polygons based on the three social neighborhoods (west $=$ green, central $=$ red, and east $=$ blue $)$.

Figure 2 visualizes the distribution of clinical signs among males in the weighted 5-m proximity network.

The k-test indicated that the male chimpanzee social network was epidemiologically relevant for the observed respiratory outbreak. Male chimpanzees with clinical signs were closer to one another in the network than expected by

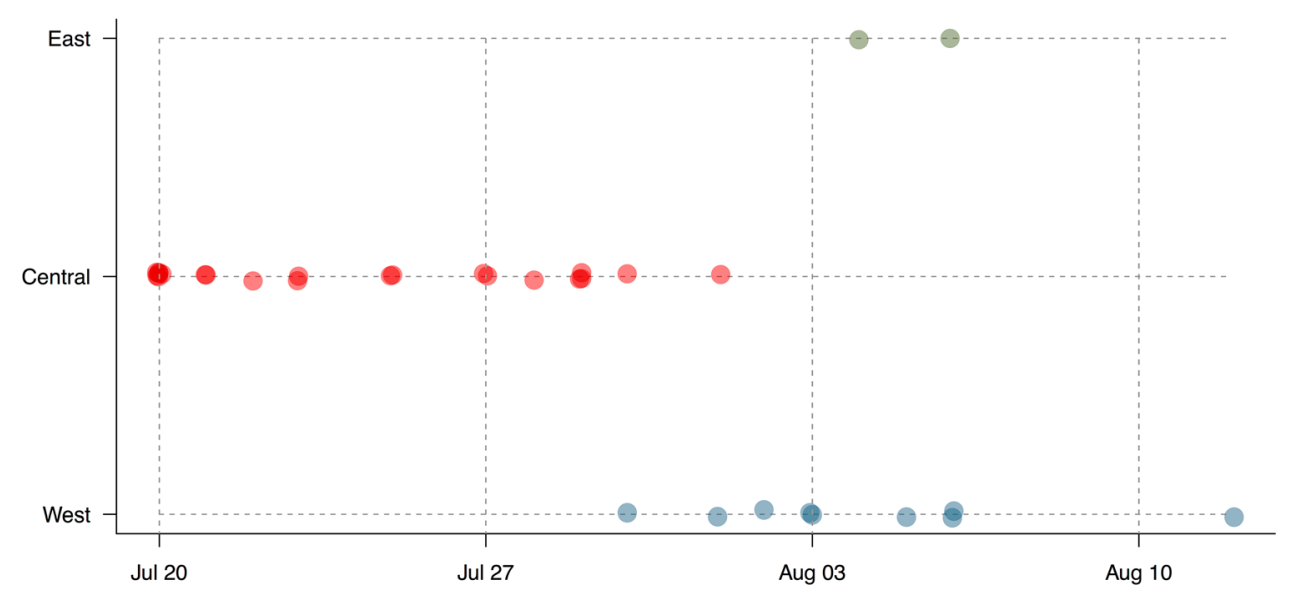

Figure 1. Timing of clinical signs in individuals based on social neighborhoods. Three social clusters emerged from the observed contact network, corresponding to three qualitative subgroups acknowledged by researchers: west, central, and east. Each shaded dot represents the first time an individual was observed with clinical signs. 
chance (mean weighted path length to nearest infections: 15.04, $P=0.014$ ) (Fig. 3).

A permutation-based multiple regression model revealed that a male chimpanzee's position in the social network, but not his rank or age, was related to the

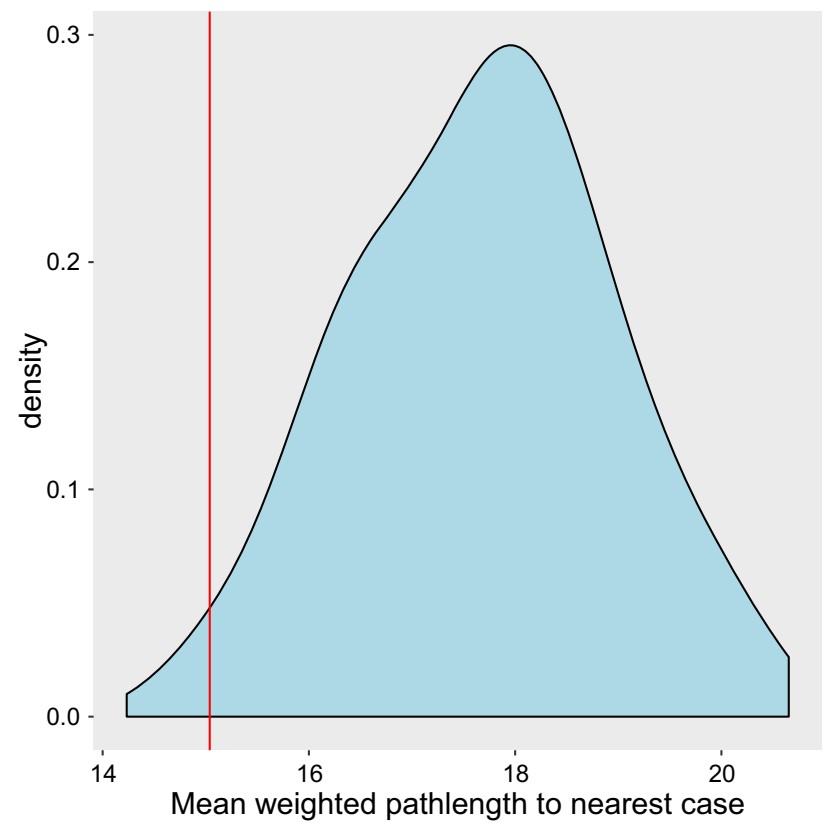

Figure 3. Graphical results of the path-based network k-test. The blue shaded area represents the null distribution of the mean distance between infected cases when the infected nodes were randomized within the network. The red vertical line represents the observed mean distance to nearest infected case. probability of exhibiting clinical signs. Individuals with high-strength centrality were more likely to exhibit clinical signs than less central male chimpanzees $\left(\beta_{\text {strength }}=9.47\right.$, $P=0.006$; Fig. 4$)$. There were minimal effects of rank $\left(\beta_{\text {rank }}=-1.14, \quad P=0.304\right)$ and age $\left(\beta_{\text {age }}=-0.031\right.$, $P=0.224)$ on the probability of exhibiting clinical signs. Although age and rank did not predict whether individuals exhibited clinical signs, these traits were positively related to network centrality. In two additional permutation-based regression models, high-ranking males exhibited greater strength centrality than low-ranking males (strength : $_{1}$ $\beta_{\text {rank }}=0.46, P<0.001$, Supplementary Figure 1), and older males exhibited greater strength centrality than younger males ( strength $_{2}$ : $\beta_{\text {age }}=0.009, P<0.001$ ).

Male chimpanzees at Ngogo were clustered into three subgroups (Fig. 2) (based on the leading non-negative eigenvector of the modularity matrix, Csardi and Nepusz 2006; Newman 2006), which represented east, central, and west "neighborhoods." There was a perfect agreement among the authors on which individual belonged to which neighborhood, and perfect agreement between the quantitative and qualitative measures of neighborhood membership. The first chimpanzees to exhibit clinical signs were all part of the central neighborhood, and clinical signs were observed in these chimpanzees from July 20 to July 30, 2015. Additional males close to the central neighborhood that are considered part of an eastern neighborhood exhibited clinical signs from August 1 to August 6, 2015.

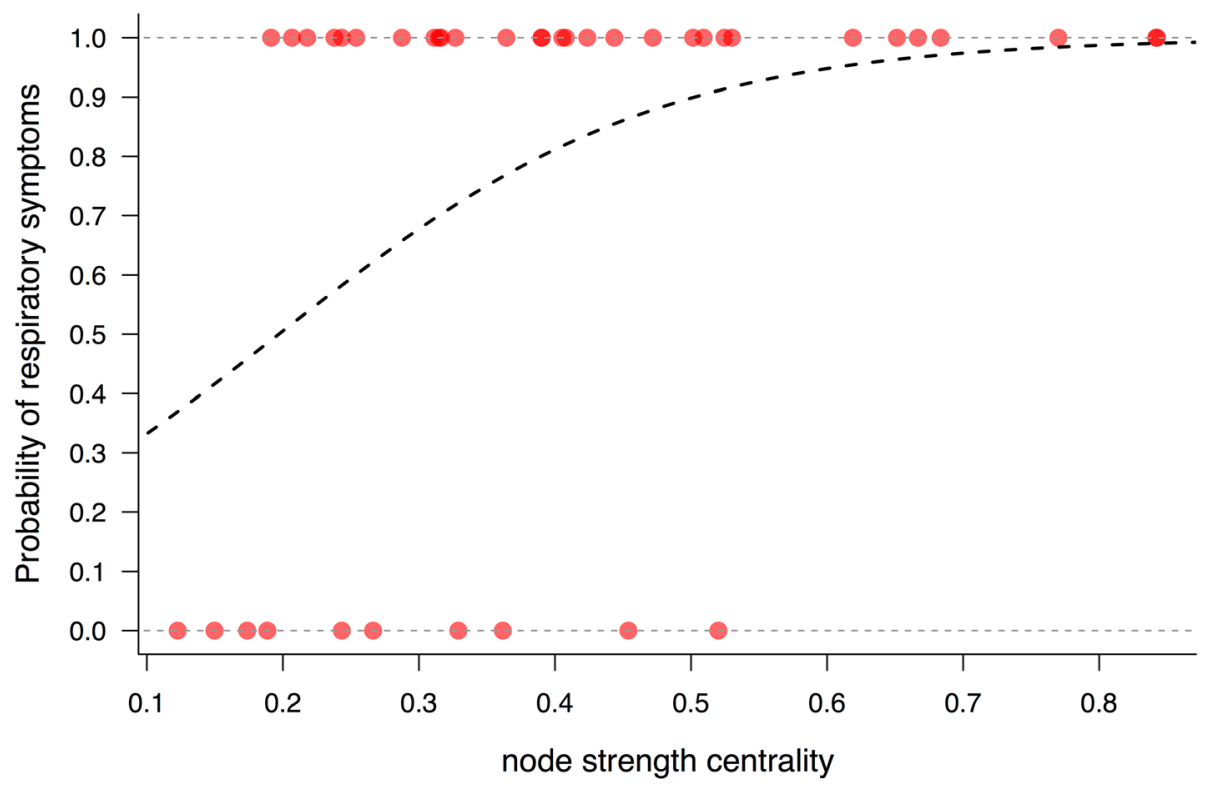

Figure 4. Network centrality strength predicts clinical signs of infection. This plot shows a fitted logistic regression of the effect of individual node strength centrality on the individual's probability of exhibiting clinical signs. Each data point represents a single chimpanzee. 
Males from the western neighborhood exhibited clinical signs from July 30 to August 12, 2015 (Fig. 1).

\section{Discussion}

The contact network, based on proximity relationships between adolescent and adult male chimpanzees, predicted which male chimpanzees exhibited respiratory infection clinical signs. Male chimpanzees that occupied central network positions were more likely to exhibit clinical signs than those less connected, whereas dominance rank and age had minimal effects on the likelihood of exhibiting clinical signs. Additional analyses revealed that high-ranking and older males were more connected in the network than lowranking and younger males, respectively, indicating a potential indirect connection with the likelihood of infection.

The findings presented here add to a growing body of evidence that an individual's social network is an important predictor of infectious disease risk. It is worth noting that this occurred during a particularly high degree of substructuring, with males from the western neighborhood and central/east neighborhoods avoiding each other for over one month. It may have been due to this high substructuring that the social network was epidemiologically relevant (Sah et al. 2017). In addition, a qualitative assessment of our data indicates a temporal component to the transmission, with the disease spreading first within neighborhoods, and only later transferred to other neighborhoods. It is possible that this clustering was related to the disease itself (Farine 2018), with chimpanzees traveling over shorter distances (e.g., vervet monkeys, Chapman et al. 2016) due to sickness behavior (e.g., lethargy in wild mice, Lopes et al. 2016) or behavioral avoidance (e.g., "self quarantine" behavior in ants, Heinze and Walter 2010). Given our understanding of long-term social dynamics in Ngogo chimpanzees, we consider it more likely that factors unrelated to disease caused the clustering. The western subgroup has since become isolated from central and eastern subgroup (Ngogo Chimpanzee Project, unpublished data), and the respiratory outbreak seems to have occurred soon after the western subgroup first exhibited signs of separating, which occurred for other social or ecological reasons.

Social relationships mediate immune health on multiple scales (Hock and Fefferman 2012; Ezenwa et al. 2016). Strong relationships may buffer individuals against infec- tion (Cohen et al. 1997; Hostinar 2015) and decrease inflammation (Kim et al. 2016), as observed in humans, or reduce parasites due to grooming, as demonstrated in macaques (Duboscq et al. 2016). Other aspects of sociality may incur costs and benefits. Our study provides indirect evidence that social status mediates exposure to infectious disease via social networks, as previously hypothesized (Rushmore et al. 2013). By achieving high rank and accruing its reproductive benefits (Boesch et al. 2006; Wroblewski et al. 2009; Langergraber et al. 2013), individuals may be exposed to infectious pathogens at higher rates due to greater sociality. Across primates, high dominance rank may increase resistance to and/or tolerance of infectious pathogens, despite potential greater exposure to pathogenic agents due to central positions in the network. High-ranking macaques exhibit more robust immune responses and lower parasite loads than low-ranking conspecifics (MacIntosh et al. 2012; Georgiev et al. 2015; Snyder-Mackler et al. 2016), while low-ranking baboons (Papio cynocephalus) exhibit slower wound healing rates (Archie et al. 2012). This trade-off may explain the results of a recent longitudinal study of respiratory infection in wild chimpanzees in which old, high-ranking males and young, low-ranking males exhibited clinical signs of infection more frequently than other age-rank classes (Emery Thompson et al. 2018). Integrating data on social behavior, immune activity, and pathogen burdens will elucidate the complex relationships affecting disease exposure and susceptibility in social animals.

Although we demonstrated links between social network position and exposure to infectious disease, there are several limitations to our study. We based our study on clinical signs of respiratory infection and did not have direct evidence of pathogen prevalence or distribution within the population. Indeed, it is possible that different individuals were infected with different pathogens, although we consider this unlikely given the temporal overlap of clinical signs. In addition, we did not have the precision to calculate the onset and recovery of disease within individuals to examine temporal trends in more detail or to derive important epidemiological parameters like the basic reproductive number $\left(R_{0}\right)$ or recovery rate.

A further limitation is that we focused only on adolescent and adult males. Accounting for all age and sex classes would offer a more complete network for analyzing transmission dynamics, and females and dependent offspring may be especially relevant for pathogen transmission among chimpanzees (De Nys et al. 2013; Rushmore et al. 
2013; Emery Thompson et al. 2018). Had we found no effect of the social network, we would not have been able to rule out the possibility that the pathogen spread via connections among females, infants, and juveniles. The fact that we still observed more connected males to be more likely to exhibit clinical signs indicates that even the limited male network was epidemiologically relevant. It remains possible, however, that our results are false positives, and accounting for females would reveal that clinical signs were distributed randomly within the network. Given that male chimpanzees tend to associate with a greater number of partners and traverse a wider range within the territory compared with females (Wrangham and Smuts 1980; Murray et al. 2007; Gilby and Wrangham 2008; Kahlenberg et al. 2008; Carne et al. 2013; Langergraber et al. 2013; Machanda et al. 2013), we consider this possibility unlikely. Although challenging to fully capture during acute respiratory infections, future studies should ideally detail complete networks, including individuals of all age and sex classes, networks at multiple social and temporal scales (Chen et al. 2014; Pinter-Wollman et al. 2014; Farine 2017, 2018), and other epidemiologically relevant traits including environmental exposure, interspecific transmission, and extra-group conspecifics (Wallis and Lee 1999; Nunn and Dokey 2006; Bonnell et al. 2010; Gogarten et al. 2019; Johnson et al. 2019). Future studies should also assess the relative contribution of social and spatial data when assessing transmission networks (Albery et al. 2020). Space use within the territory may play an important role in the spread of pathogens, and our study was limited by only using social data to construct networks.

The dynamics between sociality and disease are especially important for great apes, as disease outbreaks represent a major threat to wild populations (Vogel 2003; Leendertz et al. 2006; Nunn and Gillespie 2016). Of particular interest is the potential risk posed by human observers (Gilardi et al. 2015). A major source of mortality in gorillas and chimpanzees is from respiratory infections, and there is mounting evidence that many of these infections are from human sources (Kaur et al. 2008; Köndgen et al. 2008; Palacios et al. 2011; Grützmacher et al. 2016; Dunay et al. 2018; Negrey et al. 2019). Future studies should examine the underlying cause of disease outbreaks. Doing so requires standardizing methods to monitor health (Krief et al. 2005; Löhrich et al. 2018; Lonsdorf et al. 2018) and record social networks (White et al. 2017). All the while, human observers must maintain strict health protocols, such as wearing facemasks, sanitizing hands regularly, and avoiding entering the forest when contagious
(Gilardi et al. 2015). The combination of health monitoring, noninvasive sampling for infection, and social behavior data collection will continue to provide key insights into disease dynamics while at the same time protecting wild ape populations (Leendertz et al. 2006). Such precautions are especially important for conservationists and field biologists in light of the current coronavirus pandemic (Lappan et al. 2020; Trivedy 2020).

\section{ACKNOWLEDGEMENTS}

We thank Kim VanderWaal for assistance with methods that she developed. We thank David Watts, Rachna Reddy, and Godfrey Mbabazi for contributing data on clinical signs of the chimpanzees during this study. For additional assistance in the field, we thank Alfred Tumusiime, Lawrence Ndangizi, Ambrose Twineomujuni, Nathan Chesterman, Brian Kamugyisha, Sam Angedakin, and the late Jerry Lwanga. For comments during earlier stages, we thank Chris Schmitt and Kevin Langergraber. A.A.S. was supported by the University of Michigan, the L.S.B. Leakey Foundation, the Nacey-Maggioncalda Foundation, the National Science Foundation (1540259 and F031543). J.C.M. was supported by a National Institutes of Health grant (RO1AG049395).

\section{Authors' CONTRIButions}

A.A.S. conceived of the study, collected the data, performed the analysis, and wrote the paper. J.R. and D.C. designed and performed the analysis and wrote the paper, contributing equally to the manuscript, along with J.D.N. who conceived of the study, collected the data, contributed to the data analysis, and wrote the paper. J.C.M. collected the data and contributed to writing the paper. D.M.L. designed and performed earlier versions of the analysis and contributed to writing the paper.

\section{Compliance with Ethical Standards}

Ethical Approval All applicable institutional and/or national guidelines for the care and use of animals were followed. The study was exempt from review by the University Committee on Use and Care of Animals at the University of Michigan. The Uganda Wildlife Authority (UWA/TDO/33/02) and the Uganda National Council for Science and Technology (NS 401) approved the study. 


\section{REFERENCES}

Albery GF, Kirkpatrick L, Firth JA, Bansal S (2020) Unifying spatial and social network analysis in disease ecology. Journal of Animal Ecology. https://doi.org/10.1111/1365-2656.13356

Alexander RD (1974) The evolution of social behaviorThe evolution of social behavior. Annual Review of Ecology and Systematics 5:325-383

Altizer S, Nunn CL, Thrall PH, Gittleman JL, Antonovics J, Cunningham AA, Dobson AP, Ezenwa VO, Jones KE, Pedersen AB, Poss M, Pulliam JRC (2003) Social organization and parasite risk in mammals: integrating theory and empirical studies. Annual Review of Ecology, Evolution, and Systematics 34:517-547

Archie EA, Altmann J, Alberts SC (2012) Social status predicts wound healing in wild baboons. Proceedings of the National Academy of Sciences USA 109:9017-9022

Balasubramaniam KN, Beisner BA, Berman CM, De Marco A, Duboscq J, Koirala S, Majolo B, MacIntosh AJ, McFarland R, Molesti S (2018) The influence of phylogeny, social style, and sociodemographic factors on macaque social network structure. American Journal of Primatology 80:e22727

Balasubramaniam KN, Beisner BA, Hubbard JA, Vandeleest JJ, Atwill ER, McCowan B (2019) Affiliation and disease risk: social networks mediate gut microbial transmission among rhesus macaques. Animal Behaviour 151:131-143

Bermejo M, Rodríguez-Teijeiro JD, Illera G, Barroso A, Vilà C, Walsh PD (2006) Ebola outbreak killed 5000 gorillas. Science 314:1564-1564

Blyton MDJ, Banks SC, Peakall R, Lindenmayer DB, Gordon DM (2014) Not all types of host contacts are equal when it comes to E. coli transmission. Ecology Letters 17:970-978

Boesch C, Kohou G, Néné H, Vigilant L (2006) Male competition and paternity in wild chimpanzees of the Taï forest. Am J Phys Anthropol 130:103-115

Bonnell TR, Sengupta RR, Chapman CA, Goldberg TL (2010) An agent-based model of red colobus resources and disease dynamics implicates key resource sites as hot spots of disease transmission. Ecological Modelling 221:2491-2500

Bull CM, Godfrey SS, Gordon DM (2012) Social networks and the spread of Salmonella in a sleepy lizard population. Molecular Ecology 21:4386-4392

Butts C (2016) sna: Tools for Social Network Analysis. R package version 2.4. https://CRAN.R-project.org/package $=$ sna.

Bygott JD (1979) Agonistic behavior, dominance, and social structure in wild chimpanzees of the Gombe National Park.in D. Hamburg and E. McCown, editors. The great apes. The Benjamin/Cummings Publishing Company, Menlo Park, CA.

Caillaud D, Levréro F, Cristescu R, Gatti S, Dewas M, Douadi M, Gautier-Hion A, Raymond M, Ménard N (2006) Gorilla susceptibility to Ebola virus: The cost of sociality. Current Biology 16:R489-R491

Carne C, Semple S, Morrogh-Bernard H, Zuberbühler K, Lehmann J (2013) Predicting the vulnerability of great apes to disease: the role of superspreaders and their potential vaccination. PLOS ONE 8:e84642

Chapman CA, Friant S, Godfrey K, Liu C, Sakar D, Schoof VAM, Sengupta R, Twinomugisha D, Valenta K, Goldberg TL (2016) Social behaviours and networks of vervet monkeys are influenced by gastrointestinal parasites. PLOS ONE 11:e0161113

Chapman CA, Gillespie TR, Goldberg TL (2005) Primates and the ecology of their infectious diseases: how will anthropogenic change affect host-parasite interactions? Evolutionary Anthropology: Issues, News, and Reviews 14:134-144

Chen S, White BJ, Sanderson MW, Amrine DE, Ilany A, Lanzas C (2014) Highly dynamic animal contact network and implications on disease transmission. Scientific Reports 4:4472

Cohen S, Doyle WJ, Skoner DP, Rabin BS, Gwaltney JM (1997) Social ties and susceptibility to the common cold. JAMA 277:1940-1944

Craft ME (2015) Infectious disease transmission and contact networks in wildlife and livestock. Philosophical Transactions of the Royal Society B: Biological Sciences 370.

Craft ME, Caillaud D (2011) Network models: an underutilized tool in wildlife epidemiology? Interdisciplinary Perspectives on Infectious Diseases 2011:12

Croft DP, Darden SK, Wey TW (2016) Current directions in animal social networks. Current Opinion in Behavioral Sciences $12: 52-58$

Csardi G, Nepusz T (2006) The igraph software package for complex network research. InerJournal Complex Systems 1695.

Daszak P, Cunningham AA, Hyatt AD (2000) Emerging infectious diseases of wildlife- threats to biodiversity and human health. Science 287:443-449

De Nys HM, Calvignac-Spencer S, Thiesen U, Boesch C, Wittig RM, Mundry R, Leendertz FH (2013) Age-related effects on malaria parasite infection in wild chimpanzees. Biology Letters 9:20121160

de Waal F (1982) Chimpanzee politics: Power and Sex among Apes, New York: Harper and Row

Drewe JA (2010) Who infects whom? Social networks and tuberculosis transmission in wild meerkats Proceedings of the Royal Society B: Biological Sciences 277:633-642

Duboscq J, Romano V, Sueur C, MacIntosh AJJ (2016) Network centrality and seasonality interact to predict lice load in a social primate. Scientific Reports 6:22095

Dunay E, Apakupakul K, Leard S, Palmer JL, Deem SL (2018) Pathogen transmission from humans to great apes is a growing threat to primate conservation. EcoHealth 15:148-162

Emery Thompson M, Machanda ZP, Scully EJ, Enigk DK, Otali E, Muller MN, Goldberg TL, Chapman CA, Wrangham RW (2018) Risk factors for respiratory illness in a community of wild chimpanzees (Pan troglodytes schweinfurthii). Royal Society open science 5:180840

Ezenwa VO, Ghai RR, McKay AF, Williams AE (2016) Group living and pathogen infection revisited. Current Opinion in Behavioral Sciences 12:66-72

Farine D (2017) The dynamics of transmission and the dynamics of networks. Journal of Animal Ecology 86:415-418

Farine DR (2018) When to choose dynamic vs. static social network analysis. Journal of Animal Ecology 87:128-138

Foerster S, Franz M, Murray C, Gilby I, Feldblum J, Walker K, Pusey A (2016) Chimpanzee females queue but males compete for social status. Scientific Reports 6:35404

Fox J, Weisberg S (2019) An R Companion to Applied Regression, Sage, Thousand Oaks, CA: Third Edition edition

Freeman LC, Borgatti SP, White DR (1991) Centrality in valued graphs: A measure of betweenness based on network flow. Social Networks 13:141-154

Friant S, Ziegler TE, Goldberg TL (2016) Primate reinfection with gastrointestinal parasites: behavioural and physiological predictors of parasite acquisition. Animal Behaviour 117:105-113 
Georgiev AV, Muehlenbein MP, Prall SP, Emery Thompson M, Maestripieri D (2015) Male quality, dominance rank, and mating success in free-ranging rhesus macaques. Behavioral Ecology 26:763-772

Gilardi KV, Gillespie TR, Leendertz FH, Macfie EJ, Travis DA, Whittier CA, Williamson EA (2015) Best practice guidelines for health monitoring and disease control in great ape populations. Occasional Papers of the IUCN Species Survival Commission 56.

Gilby IC, Wrangham RW (2008) Association patterns among wild chimpanzees (Pan troglodytes schweinfurthii) reflect sex differences in cooperation. Behavioral Ecology and Sociobiology 62:1831-1842

Gogarten JF, Düx A, Mubemba B, Pléh K, Hoffmann C, Mielke A, Müller-Tiburtius J, Sachse A, Wittig RM, Calvignac-Spencer S, Leendertz FH (2019) Tropical rainforest flies carrying pathogens form stable associations with social nonhuman primates. Molecular Ecology 28:4242-4258

Goodall J (1986) The chimpanzees of Gombe: patterns of behavior, Cambridge, MA: Harvard University Press

Grützmacher KS, Köndgen S, Keil V, Todd A, Feistner A, Herbinger I, Petrzelkova K, Fuh T, Leendertz SA, Calvignac-Spencer S, Leendertz FH (2016) Codetection of respiratory syncytial virus in habituated wild western lowland gorillas and humans during a respiratory disease outbreak. EcoHealth 13:499-510

Habig B, Archie EA (2015) Social status, immune response and parasitism in males: a meta-analysis. Philosophical Transactions of the Royal Society B: Biological Sciences 370:20140109

Heinze J, Walter B (2010) Moribund ants leave their nests to die in social isolation. Current Biology 20:249-252

Hock K, Fefferman NH (2012) Social organization patterns can lower disease risk without associated disease avoidance or immunity. Ecological Complexity 12:34-42

Hostinar CE (2015) Recent developments in the study of social relationships, stress responses, and physical health. Current Opinion in Psychology 5:90-95

Johnson EE, Escobar LE, Zambrana-Torrelio C (2019) An ecological framework for modeling the geography of disease transmission. Trends in Ecology \& Evolution 34:655-668

Kahlenberg SM, Thompson ME, Wrangham RW (2008) Female competition over core areas in Pan troglodytes schweinfurthii, Kibale National Park. Uganda. International Journal of Primatology 29:931

Kappeler PM, Cremer S, Nunn CL (2015) Sociality and health: impacts of sociality on disease susceptibility and transmission in animal and human societies. Philosophical Transactions of the Royal Society B: Biological Sciences 370.

Kaur T, Singh J, Tong S, Humphrey C, Clevenger D, Tan W, Szekely B, Wang Y, Li Y, Alex Muse E, Kiyono M, Hanamura S, Inoue E, Nakamura M, Huffman MA, Jiang B, Nishida T (2008) Descriptive epidemiology of fatal respiratory outbreaks and detection of a human-related metapneumovirus in wild chimpanzees (Pan troglodytes) at Mahale Mountains National Park, Western Tanzania. American Journal of Primatology 70:755-765

Kim DA, Benjamin EJ, Fowler JH, Christakis NA (2016) Social connectedness is associated with fibrinogen level in a human social network. Proceedings of the Royal Society B: Biological Sciences 283:20160958

Köndgen S, Kühl H, N'Goran PK, Walsh PD, Schenk S, Ernst N, Biek R, Formenty P, Mätz-Rensing K, Schweiger B, Junglen S, Ellerbrok H, Nitsche A, Briese T, Lipkin WI, Pauli G, Boesch C, Leendertz FH (2008) Pandemic human viruses cause decline of endangered great apes. Current Biology 18:260-264
Krause J, Ruxton GD (2002) Living in groups, Oxford: Oxford University Press

Krief S, Huffman MA, Sévenet T, Guillot J, Bories C, Hladik CM, Wrangham RW (2005) Noninvasive monitoring of the health of Pan troglodytes schweinfurthii in the Kibale National Park, Uganda. International Journal of Primatology 26:467-490

Kuehl HS, Elzner C, Moebius Y, Boesch C, Walsh PD (2008) The price of play: self-organized infant mortality cycles in chimpanzees. PLOS ONE 3:e2440

Langergraber K, Mitani J, Watts D, Vigilant L (2013) Male-female socio-spatial relationships and reproduction in wild chimpanzees. Behavioral Ecology and Sociobiology 67:861-873

Leendertz FH, Ellerbrok H, Boesch C, Couacy-Hymann E, MätzRensing K, Hakenbeck R, Bergmann C, Abaza P, Junglen S, Moebius Y, Vigilant L, Formenty P, Pauli G (2004) Anthrax kills wild chimpanzees in a tropical rainforest. Nature 430:451

Leendertz FH, Pauli G, Maetz-Rensing K, Boardman W, Nunn C, Ellerbrok H, Jensen SA, Junglen S, Christophe B (2006) Pathogens as drivers of population declines: The importance of systematic monitoring in great apes and other threatened mammals. Biological Conservation 131:325-337

Lappan S, Malaivijitnond S, Radhakrishna S, Riley EP, Ruppert N (2020) The human-primate interface in the New Normal: Challenges and opportunities for primatologists in the COVID19 era and beyond. American Journal of Primatology 82:e23176

Löhrich T, Behringer V, Wittig RM, Deschner T, Leendertz FH (2018) The use of neopterin as a noninvasive marker in monitoring diseases in wild chimpanzees. EcoHealth 15:792-803

Lonsdorf EV, Gillespie TR, Wolf TM, Lipende I, Raphael J, Bakuza J, Murray CM, Wilson ML, Kamenya S, Mjungu D, Collins DA, Gilby IC, Stanton MA, Terio KA, Barbian HJ, Li Y, Ramirez M, Krupnick A, Seidl E, Goodall J, Hahn BH, Pusey AE, Travis DA (2018) Socioecological correlates of clinical signs in two communities of wild chimpanzees (Pan troglodytes) at Gombe National Park. Tanzania. American Journal of Primatology 80:e22562

Lopes PC, Block P, König B (2016) Infection-induced behavioural changes reduce connectivity and the potential for disease spread in wild mice contact networks. Scientific Reports 6:31790

Machanda ZP, Gilby IC, Wrangham RW (2013) Male-Female association patterns among free-ranging chimpanzees (Pan troglodytes schweinfurthii). International Journal of Primatology 34:917-938

MacIntosh AJJ, Jacobs A, Garcia C, Shimizu K, Mouri K, Huffman MA, Hernandez AD (2012) Monkeys in the middle: parasite transmission through the social network of a wild primate. PLOS ONE 7:e51144

Muehlenbein MP, Watts DP (2010) The costs of dominance: testosterone, cortisol and intestinal parasites in wild male chimpanzees. BioPsychoSocial Medicine 4:21

Muller MN, Thompson ME, Wrangham RW (2006) Male chimpanzees prefer mating with old females. Current Biology $16: 2234-2238$

Murray CM, Mane SV, Pusey AE (2007) Dominance rank influences female space use in wild chimpanzees, Pan troglodytes: towards an ideal despotic distribution. Animal Behaviour 74:1795-1804

Negrey JD, Reddy RB, Scully EJ, Phillips-Garcia S, Owens LA, Langergraber KE, Mitani JC, Emery Thompson M, Wrangham RW, Muller MN, Otali E, Machanda Z, Hyeroba D, Grindle KA, Pappas TE, Palmenberg AC, Gern JE, Goldberg TL (2019) Simultaneous outbreaks of respiratory disease in wild chim- 
panzees caused by distinct viruses of human origin. Emerging Microbes \& Infections 8:139-149

Newman M (2010) Networks: an introduction, New York: Oxford University Press

Newman ME (2006) Finding community structure in networks using the eigenvectors of matrices. Physical review E 74:036104

Nishida T (1968) The social group of wild chimpanzees in the Mahali Mountains. Primates 9:167-224

Nunn C, Gillespie TR (2016) Infectious disease and primate conservation.iI Wich SA, Marshall AJ, editors. An Introduction to Primate Conservation. Oxford University Press, Oxford.

Nunn CL, Dokey AT-W (2006) Ranging patterns and parasitism in primates. Biology Letters 2:351-354

Nunn CL, Thrall PH, Stewart K, Harcourt AH (2008) Emerging infectious diseases and animal social systems. Evolutionary Ecology 22:519-543

Palacios G, Lowenstine LJ, Cranfield MR, Gilardi KV, Spelman L, Lukasik-Braum M, Kinani JF, Mudakikwa A, Nyirakaragire E, Bussetti AV, Savji N, Hutchison S, Egholm M, Lipkin WI (2011) Human metapneumovirus infection in wild mountain gorillas, Rwanda. Emerging infectious diseases 17:711-713

Perofsky AC, Lewis RJ, Abondano LA, Di Fiore A, Meyers LA (2017) Hierarchical social networks shape gut microbial composition in wild Verreaux's sifaka. Proceedings of the Royal Society B: Biological Sciences 284.

Pinter-Wollman N, Hobson EA, Smith JE, Edelman AJ, Shizuka D, De Silva S, Waters JS, Prager SD, Sasaki T, Wittemyer G (2014) The dynamics of animal social networks: analytical, conceptual, and theoretical advances. Behavioral Ecology 25:242-255

Powell SN, Wallen MM, Miketa ML, Krzyszczyk E, Foroughirad V, Bansal S, Mann J (2019) Sociality and tattoo skin disease among bottlenose dolphins in Shark Bay, Australia. Behavioral Ecology.

R Core Team (2018) R: A language and environment for statistical computing, Vienna, Austria: R Foundation for Statistical Computing

Reynolds JJH, Hirsch BT, Gehrt SD, Craft ME (2015) Raccoon contact networks predict seasonal susceptibility to rabies outbreaks and limitations of vaccination. Journal of Animal Ecology 84:1720-1731

Rifkin JL, Nunn CL, Garamszegi LZ (2012) Do animals living in larger groups experience greater parasitism? A meta-analysis The American Naturalist 180:70-82

Rimbach R, Bisanzio D, Galvis N, Link A, Di Fiore A, Gillespie TR (2015) Brown spider monkeys (Ateles hybridus): a model for differentiating the role of social networks and physical contact on parasite transmission dynamics. Philosophical Transactions of the Royal Society B: Biological Sciences 370.

Romano V, Duboscq J, Sarabian C, Thomas E, Sueur C, MacIntosh AJJ (2016) Modeling infection transmission in primate networks to predict centrality-based risk. American Journal of Primatology 78:767-779

Rushmore J, Bisanzio D, Gillespie TR (2017) Making new connections: insights from primate-parasite networks. Trends in Parasitology 33:547-560

Rushmore J, Caillaud D, Hall RJ, Stumpf RM, Meyers LA, Altizer S (2014) Network-based vaccination improves prospects for disease control in wild chimpanzees. Journal of The Royal Society Interface 11.
Rushmore J, Caillaud D, Matamba L, Stumpf RM, Borgatti SP, Altizer S (2013) Social network analysis of wild chimpanzees provides insights for predicting infectious disease risk. Journal of Animal Ecology 82:976-986

Sah P, Leu ST, Cross PC, Hudson PJ, Bansal S (2017) Unraveling the disease consequences and mechanisms of modular structure in animal social networks. Proceedings of the National Academy of Sciences 114:4165-4170

Salazar MFM, Waldner C, Stookey J, Bollinger TK (2016) Infectious disease and grouping patterns in mule deer. PLOS ONE 11:e0150830

Scully EJ, Basnet S, Wrangham RW, Muller MN, Otali E, Hyeroba D, Grindle KA, Pappas TE, Thompson ME, Machanda Z (2018) Lethal respiratory disease associated with human rhinovirus $C$ in wild chimpanzees, Uganda, 2013. Emerging infectious diseases 24:267

Smith KF, Acevedo-Whitehouse K, Pedersen AB (2009) The role of infectious diseases in biological conservation. Animal Conservation 12:1-12

Snyder-Mackler N, Sanz J, Kohn JN, Brinkworth JF, Morrow S, Shaver AO, Grenier J-C, Pique-Regi R, Johnson ZP, Wilson ME, Barreiro LB, Tung J (2016) Social status alters immune regulation and response to infection in macaques. Science 354:10411045

Springer A, Kappeler PM, Nunn CL (2017) Dynamic vs. static social networks in models of parasite transmission: predicting Cryptosporidium spread in wild lemurs. Journal of Animal Ecology 86:419-433

Springer A, Mellmann A, Fichtel C, Kappeler PM (2016) Social structure and Escherichia coli sharing in a group-living wild primate, Verreaux's sifaka. BMC Ecology 16:6

Struhsaker TT (1997) Ecology of an African rain forest: logging in Kibale and the conflict between conservation and exploitation, Gainesville, FL: University of Florida Press

Thompson ME, Kahlenberg SM, Gilby IC, Wrangham RW (2007) Core area quality is associated with variance in reproductive success among female chimpanzees at Kibale National Park. Animal Behaviour 73:501-512

Trivedy C (2020) Is 2020 the year when primatologists should cancel fieldwork? A reply. American Journal of Primatology 82:e23173

Tung J, Barreiro LB, Johnson ZP, Hansen KD, Michopoulos V, Toufexis D, Michelini K, Wilson ME, Gilad Y (2012) Social environment is associated with gene regulatory variation in the rhesus macaque immune system. Proceedings of the National Academy of Sciences 109:6490-6495.

VanderWaal K, Enns EA, Picasso C, Packer C, Craft ME (2016) Evaluating empirical contact networks as potential transmission pathways for infectious diseases. Journal of The Royal Society Interface 13.

VanderWaal KL, Atwill ER, Isbell LA, McCowan B (2014) Linking social and pathogen transmission networks using microbial genetics in giraffe (Giraffa camelopardalis). Journal of Animal Ecology 83:406-414

Vogel G (2003) Can great apes be saved from Ebola? Science 300:1645-1645

Wakefield ML (2008) Grouping patterns and competition among female Pan troglodytes schweinfurthii at Ngogo, Kibale National Park, Uganda. International Journal of Primatology 29:907-929

Wallis J, Lee DR (1999) Primate conservation: the prevention of disease transmission. International Journal of Primatology 20:803-826 
Webber QMR, Brigham RM, Park AD, Gillam EH, O'Shea TJ, Willis CKR (2016) Social network characteristics and predicted pathogen transmission in summer colonies of female big brown bats (Eptesicus fuscus). Behavioral Ecology and Sociobiology 70:701-712

White LA, Forester JD, Craft ME (2017) Using contact networks to explore mechanisms of parasite transmission in wildlife. Biological Reviews 92:389-409

Williams JM, Lonsdorf EV, Wilson ML, Schumacher-Stankey J, Goodall J, Pusey AE (2008) Causes of death in the Kasekela chimpanzees of Gombe National Park, Tanzania. American Journal of Primatology 70:766-777

Wolfe ND, Escalante AA, Karesh WB, Kilbourn A, Spielman A, Lal AA (1998) Wild primate populations in emerging infectious disease research: the missing link? Emerging infectious diseases 4:149-158
Wood BM, Watts DP, Mitani JC, Langergraber KE (2017) Favorable ecological circumstances promote life expectancy in chimpanzees similar to that of human hunter-gatherers. Journal of Human Evolution 105:41-56

Wrangham RW, Smuts BB (1980) Sex differences in the behavioural ecology of chimpanzees in the Gombe National Park, Tanzania. Journal of reproduction and fertility. Supplement:13.

Wroblewski EE, Murray CM, Keele BF, Schumacher-Stankey JC, Hahn BH, Pusey AE (2009) Male dominance rank and reproductive success in chimpanzees, Pan troglodytes schweinfurthii. Animal Behavior 77:873-885

Zohdy S, Kemp AD, Durden LA, Wright PC, Jernvall J (2012) Mapping the social network: tracking lice in a wild primate (Microcebus rufus) population to infer social contacts and vector potential. BMC Ecology 12:4 